\title{
Repurposing the Thalidomide to the Treatment of Irinotecan-Induced Intestinal Mucositis: An Old Drug to a New Use
}

\author{
Rafaela Miranda Pessoa\#, William Gustavo Lima\#, Kátia Duarte Vital, Valbert Nascimento Cardoso and Simone \\ Odília Antunes Fernandes*
}

Department of Clinical and Toxicological Analyses, University of Minas Gerais, Brazil

\#These authors contributed equally.

Submission: August 31, 2018; Published: October 09, 2018

*Corresponding author: Simone Odília Antunes, Radioisotope Laboratory, Department of Clinical and Toxicological Analyses, School of Pharmacy, Federal University of Minas Gerais, Av. Antônio Carlos, Brazil, Tel: 55-313409-6893/3409-6904; Email: simoneodilia@yahoo.com.br

\begin{abstract}
Intestinal mucositis (IM) is an inflammation caused by antitumor therapy, it seems as side effect especially in irinotecan-based protocols. This condition has a negative impact on patient's quality of life and treatment effectiveness, once restricts food intake and may predispose the patient to secondary infections. Currently in the clinical practice, only palliative measures are used to treat the IM, which represent the main clinical limitation in management this condition. In this scenario, the repurposing of compounds that are already in clinical use highlight as a rapid and effective strategy against IM caused by chemotherapy. The use of thalidomide has already been demonstrated as a good therapeutic option in preclinical models of irinotecan-induced IM, due its ability to modulate proinflammatory response and to reduce the levels of enterotoxic metabolite of this antitumor agent (i.e., SN-38). In this sense, thalidomide appears as a promising compound for repositioning the therapy of IM, since it exhibits high clinical efficacy and does not affect the activity of ongoing antitumor treatment.
\end{abstract}

Keywords: Intestinal mucositis; Irinotecan; Thalidomide; Cancer therapy

Abbreviations: IM: Intestinal Mucositis; TNF- $\alpha$ : Tumor Necrosis Factor Alfa; IL-1 $\beta$ : Interleukin 1 Beta; IL-6: Interleukin 6; IFN-Г: Interferon Gamma; IL-2: Interleukin 2; IL-18: Interleukin 18; RNA: Ribonucleic Acid

\section{Introduction}

Intestinal mucositis (IM) is an adverse reaction characterized by acute inflammation of mucosa in small intestine and/or colon induced by a variety of chemotherapeutic agents, particularly irinotecan and 5-fluorouracil [1]. This condition has a great impact on patient's quality of life, since it limits their tolerability to antineoplastic therapy, restricts food intake (i.e., has been associated to fatigue and sub nutrition), and may predispose the patient to secondary infections, thus generating an increase in time of hospital stay and higher cost to public health [1,2]. As the first-line treatment for colorectal cancer, the clinical benefit of irinotecan is many times limited by IM, which occurs in $15-40 \%$ of patients that receiving conventional doses and virtually all on the regimens of high-doses this antitumor $[2,3]$.

Among the main limitations in the clinical management of IM is the absence of curative or prophylactic treatments that are effective and safe in these cases, being available only palliative measures currently [2]. In this direction, the search for new pharmacotherapeutic strategies become imperative to reduce the morbidity and mortality associated with IM and ensure a better quality of life for patients susceptible to this manifestation. Recently, the concept of repurposing is gaining space in the pharmaceutical market by allowing the reduction of costs, optimization of release time for the regulatory agencies and reducing the final price of new drugs [4]. In this development model, compounds that are already in clinical use are diverted from your original employment and assigned to a new application, being required only clinical trials demonstrating the effectiveness of the new use $[4,5]$.

While the activity of many non-enteroprotective drugs has been recognized, only now the interest in exploring these compounds in the treatment of IM is increasing [6]. The thalidomide, a derivative of glutamic acid that is widely employed in the treatment of inflammatory and autoimmune diseases, has showed as a good therapeutic option also in IM [7]. Govindarajan and collaborators [8] observed that the combination of thalidomide and irinotecan in patients with metastatic colorectal cancer eliminated the diarrhea and nausea associated to the treatment, thereby ensuring that the patients completed the 
chemotherapy course without suspensions or reduction in dose of drug. This clinical evidence indicates that thalidomide might increase the tolerability to antineoplasic therapy preventing the IM, and basic studies have confirmed these findings.

In mice with irinotecan-induced IM $(75 \mathrm{mg} / \mathrm{kg} /$ day for four days), the treatment with thalidomide $(60 \mathrm{mg} / \mathrm{kg} /$ day for 7 days, starting 1 day before the first antitumor injection) was able to reduce the inflammatory process in the ileum, but did not reduce late-onset diarrhea associated with chemotherapy [9]. On the other hand, co-administration of thalidomide $(100 \mathrm{mg} / \mathrm{kg} /$ day for 8 days, starting 1 day before the first antitumor injection) and irinotecan (60 mg/kg/day for four days) in SpragueDawley rats produced a considerable reduction in diarrhea and weight loss associated with chemotherapy, as well as protecting animals from other adverse reactions of the antitumor, such as myelosuppression, inflammation of the intestinal mucosa, and apoptosis of enteric epithelial cells. In these animals, the mechanisms involved were the TNF- $\alpha$, IL- $1 \beta$, IL- 6 and IFN- $\gamma$ inhibition, and activation of IL-2 [10].

Importantly, thalidomide treatment did not reduce the antitumor effect of irinotecan, and in C57BL/6 mice the use this drug was able to protect the weight loss and intestinal damage, as well as speed up the intestinal epithelia renovation without affecting efficacious of tumor growth inhibition by irinotecan [11]. The biochemical mechanisms that support the therapeutic effect of thalidomide have been associated with the ability of this drug to modulate the proinflammatory response in IM, as well as to modify the pharmacokinetics of the irinotecan, reducing its enterotoxic fraction [9-14]. Thalidomide is known by inhibits TNF- $\alpha$ production, a key cytokine in irinotecan-induced IM, by enhancing the degradation of its messenger RNA [7]. In addition, thalidomide has been associated to inhibition of inflammasome, an important proinflammatory system that leads to maturation and secretion of cytokines associated with IM such as IL-1 $\beta$ and IL-18 [11]. Recent studies have also showed that the hydrolytic products of thalidomide interfere with the pharmacokinetics of irinotecan, which was associated to the enteroprotective effect of this drug [12]. Irinotecan is a prodrug which is activated to the metabolite SN-38 thought of hepatic carboxylesterases. In addition to a higher cytotoxic effect that irinotecan, SN-38 is characterized also by high enterotoxicity, been it related to IM [13]. The metabolites of thalidomide decreasing the systemic exposure of SN-38, reducing half-life and inducing intracellular accumulation of this active metabolite in liver, besides diminishing the biliary excretion and cecal exposure of both, irinotecan and SN-38 [12-14] (Figure 1).

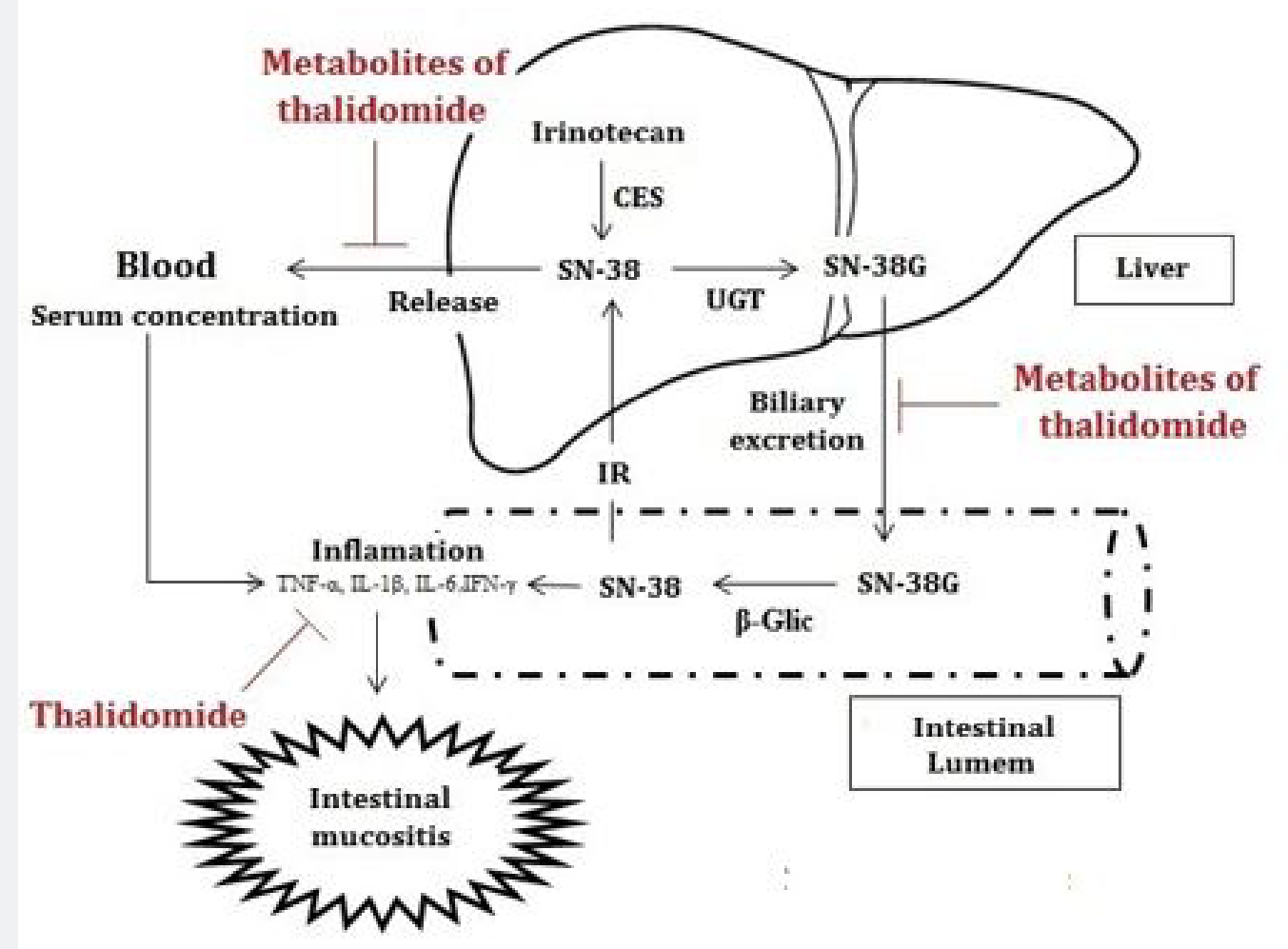

Figure 1: The schematic representation of main mechanisms associated to enteroprotective effect of thalidomide and its metabolites in irinotecan-induced intestinal mucositis. Hydrolytic products of thalidomide inhibit the release of SN-38 obtained by action of hepatic carboxylesterase on irinotecan, thus inducing intracellular accumulation of this metabolite in liver. In addition, thalidomide diminish the biliary excretion and cecal exposure ofs enterotoxin metabolite of irinotecan (i.e., SN-38). Thalidomide act also directly on intestinal cells inhibiting the inflammatory process through of reduction in proinflammatory cytokines expression (TNF- $\alpha$, IL-1 $\beta$, IL-6 and IFN- $\gamma$ ), stimulate to release of anti-inflammatory cytokines (IL-2), inhibition of inflammasomes, and degradation of mRNA of TNF- $\alpha$.

CES: Carboxylesterases; UGT: UDP-Glucuronosyltransferase; $\beta$-Glic: Microbial $\beta$-Glucuronidase 


\section{Global Journal of Pharmacy \& Pharmaceutical Sciences}

\section{Conclusion}

Despite recent advances in the development of prophylactic and curative treatments for irinotecan-induced IM, no universally effective and safe drug is currently licensed in these cases. The fact that the IM is the acute disease limits the time required for the use of therapeutic compounds, which reduces the interest of large pharmaceutical companies in investing to research and development of news drugs directed to these chemotherapyassociated adverse reactions. Thus the repositioning stands out as a strategy that aims to dribble the incipient investments of pharmaceutical companies, as well as the strict legislation applied to the release of new compounds in market. The antiinflammatory effect and the ability of thalidomide to reduce the plasma concentration of the enterotoxic metabolite of irinotecan are shown to have a profound impact on the development of IM. In this context, we can conclude that thalidomide appears as a promising compound for repositioning the therapy of IM, since it exhibits high clinical efficacy and does not affect the activity of ongoing antitumor treatment.

\section{Acknowledgement}

We would like to thank Conselho Nacional de Desenvolvimento Cientifico and Tecnologico (CNPq), Coordenacao de Aperfeicoamento de Pessoal de Nivel Superior (CAPES), and Fundacao de Amparo a Pesquisa do estado de Minas Gerais (FAPEMIG) by financial support. RMP and WGL are grateful to CAPES for a graduate fellowship.

\section{Conflict of Interest}

All authors declared that there are no financial or other contractual agreements that might cause conflicts of interest or be perceived as causing conflicts of interest.

\section{References}

1. Villa A, Sonis ST (2015) Mucositis: pathobiology and management. Curr Opin Oncol 27(3): 159-164.

2. Cinausero M, Aprile G, Ermacora P, Basile D, Vitale MG, et al. (2017) New Frontiers in the Pathobiology and Treatment of Cancer Regimen Related Mucosal Injury. Front Pharmacol 8(8): 354.

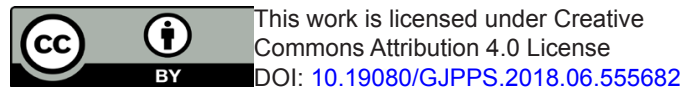

3. Kwon Y (2016) Mechanism-Based Management for Mucositis: Option for Treating Side Effects without Compromising the Efficacy of Cancer Therapy. Onco Targets Ther 5(9): 2007-2016.

4. Hernandez JJ, Pryszlak M, Smith L, Yanchus C, Kurji N, et al. (2017) Giving Drugs a Second Chance: Overcoming Regulatory and Financial Hurdles in Repurposing Approved Drugs as Cancer Therapeutics. Front Oncol 7: 273.

5. Corsello SM, Bittker JA, Liu Z, Gould J, McCarren P, et al. (2017) The Drug Repurposing Hub: a next-generation drug library and information resource. Nat Med 23(4): 405-408.

6. Swami U, Goel S, Mani S (2013) Therapeutic Targeting of CPT-11 Induced Diarrhea: A Case for Prophylaxis. Curr Drug Target 14(7): 777-797.

7. Sampaio EP, Sarno EN, Galilly R, Cohn ZA, Kaplan G (1991) Thalidomide selectively inhibits tumor necrosis factor $\alpha$ production by stimulated human monocytes. J Exp Med 173(3): 699-703.

8. Govindarajan R, Heaton KM, Broadwater R, Zeitlin A, Lang NP, et al. (2000) Effect of thalidomide on gastrointestinal toxic effects of irinotecan. Lancet 356(9229): 566-567.

9. Melo ML, Brito GA, Soares RC, Carvalho SB, Silva JV, et al. (2008) Role of cytokines (TNF-alpha, IL-1beta and KC) in the pathogenesis of CPT11-induced intestinal mucositis in mice: effect of pentoxifylline and thalidomide. Cancer Chemother Pharmacol 61(5): 775-784.

10. Yang XX, Hu ZP, Xu AL, Duan W, Zhu YZ, et al. (2006) A Mechanistic Study on Reduced Toxicity of Irinotecan by Coadministered Thalidomide, a Tumor Necrosis Factor-Alpha Inhibitor. J Pharmacol Exp Ther 319(1): 82-104.

11. Lian Q, Xu J, Yan S, Huang M, Ding H, et al. (2017) ChemotherapyInduced Intestinal Inflammatory Responses are Mediated by Exosome Secretion of Double-Strand DNA via AIM2 Inflammasome Activation. Cell Res 27(6): 784-800.

12. Yang XX, Hu ZP, Xu AL, Duan W, Zhu YZ, et al. (2006) A Mechanistic Study on Reduced Toxicity of Irinotecan by Coadministered Thalidomide, a Tumor Necrosis Factor-Alpha Inhibitor. J Pharmacol Exp Ther 319(1): 82-104.

13. Yamamoto M, Kurita A, Asahara T, Takakura A, Katono K, et al. (2008) Metabolism of Irinotecan and its Active Metabolite SN-38 by Intestinal Microflora in Rats. Oncol Rep 20(4): 727-730.

14. Yang XX, Hu ZP, Chan SY, Duan W, Ho PC, et al. (2006) Pharmacokinetic Mechanisms for Reduced Toxicity of Irinotecan by Coadministered Thalidomide. Curr Drug Metab 7(4): 431-455.

\section{Your next submission with Juniper Publishers will reach you the below assets}

- Quality Editorial service

- Swift Peer Review

- Reprints availability

- E-prints Service

- Manuscript Podcast for convenient understanding

- Global attainment for your research

- Manuscript accessibility in different formats

( Pdf, E-pub, Full Text, Audio)

- Unceasing customer service

Track the below URL for one-step submission https://juniperpublishers.com/online-submission.php 